Revista de la red interuniversitaria de estudios sobre las literaturas rioplatenses contemporáneas en Francia

$11 \mid 2014$

De niños e infancias

\title{
Las nenas terribles de Silvina Ocampo y Marosa di Giorgio
}

José Amícola

\section{OpenEdition}

\section{Journals}

Edición electrónica

URL: http://journals.openedition.org/lirico/1847

DOI: $10.4000 /$ lirico. 1847

ISSN: 2262-8339

Editor

Réseau interuniversitaire d'étude des littératures contemporaines du Río de la Plata

\section{Referencia electrónica}

José Amícola, «Las nenas terribles de Silvina Ocampo y Marosa di Giorgio », Cuadernos LIRICO [En línea], 11 | 2014, Puesto en línea el 01 diciembre 2014, consultado el 19 abril 2019. URL : http:// journals.openedition.org/lirico/1847; DOI : 10.4000/lirico.1847

Este documento fue generado automáticamente el 19 abril 2019.

\section{(c) $(1) \odot \ominus$}

Cuadernos LIRICO está distribuido bajo una Licencia Creative Commons Atribución-NoComercialSinDerivar 4.0 Internacional. 


\title{
Las nenas terribles de Silvina Ocampo y Marosa di Giorgio
}

\author{
José Amícola
}

1 "La reja del ascensor tenía flores con cáliz dorado y follajes rizados de fierro negro, donde se enganchan los ojos cuando uno está triste viendo desenvolverse, hipnotizados por las grandes serpientes, los cables del ascensor." (Silvina Ocampo/Matilde Sánchez, 1991 : 23). Así comienza el cuento "Cielo de claraboyas" (1937) de Silvina Ocampo (1903-1993), una escritora argentina nacida en el seno de una familia patricia, en cuyos cuentos los protagonistas son en muchos casos niñas de la alta burguesía de Buenos Aires que muestran sus ilusiones e intrigas hacia 1900. En el caso de este relato breve, como muchos salidos de su pluma, la narración se gesta a partir de una mirada bizca. Se tratará aquí en la mayor parte del cuento de la visión de una niña que interpreta los hechos que se suceden sobre su cabeza a partir de una perspectiva que, en definitiva, termina siendo poética y mágica. Este relato presenta, entonces, gracias a una narración entrecortada, sombras que se adivinan a través del suelo casi traslúcido del piso superior al que vive la pequeña narradora. El apartamento de encima del suyo presenta un cuadrado de interpretación en ese marco que da el piso vidriado, sobre el que se proyectan, como en la pantalla de un cine, ansias, rencores y acciones humanas, a las que se le adjudican movimientos animalizados. Zapatos, faldas, rodillas pasan a ser, así, signos de un tratado semiológico infantil cuyos sememas peligrosos se articulan alrededor del blanco, negro y rojo, en sentido creciente de animosidad. La relación de los individuos que habitan el piso superior se articula a través de las transparencias: tres pares de zapatos adultos se arremolinan alrededor de un par de pies calzados con zapatos infantiles. La conformación de esa familia (entrevista a través del vidrio lechoso) se va a ir revelando a medida que nos acerquemos al final del relato: se trata de un matrimonio con una niña, pero a esa constelación triádica se agrega la figura "gótica" de una mujer amenazante con botines negros, a la que se le adjunta una mancha de sangre que se va extendiendo sobre el vidrio casi traslúcido (el piso del apartamento superior es el techo desde el apartamento en que eso se mira). El terror infantil ante la represión autoritaria de la "gobernanta" se llena con la tradición al estilo del relato de Henry James "The Turn of the Screw". En la coda final sabremos que la narradora reconoce realmente a dos de esas figuras por haberlas 
visto en una plaza cercana, territorio de los juegos infantiles, al estilo de los personajes del primer volumen del ciclo de Marcel Proust. La institutriz y la niña del apartamento espiado se materializan, entonces, como las protagonistas de la "proyección del piso superior" (el cielo de claraboyas) y se llaman Leonor y Celestina, según nos informa finalmente la narradora. De Leonor se dice que puede ser una institutriz o una tía "disfrazada". De Celestina sabremos solamente que se halla en estado de indefensión, como sucede con los niños en las obras de Silvina Ocampo (y Henry James). Celestina es probablemente de la misma edad de la narradora; las manchas de su sangre aparecerán marcadas en el vidrio del piso traslúcido a causa del accidente (¿o asesinato ?) causado por la figura inquietante de la mujer que debe cuidarla.

2 En el comienzo del cuento, citado al principio de estas reflexiones, cunde el ambiente ominoso en ciertos elementos subyacentes entre las metáforas y personificaciones: los cables del ascensor cobran vida y parecen dispuestos a estrangular a quien se acerque a ellos, los dibujos de las rejas antiguas del ascensor encerrado en esa jaula pueden prenderse de los ojos de quienes los miran porque parecen actuar como anzuelos. Si la puesta en suspenso del relato empieza por su principio, este comienzo podría muy bien encajar en otro tipo de narración que aludiera a la narrativa de terror. La casa del relato es antigua y sus protagonistas parecen detenidas en la moda y costumbres de comienzos del siglo XIX, época de la infancia de la autora, nacida en 1903.

3 Este cuento hace intervenir, pues, la tradición gótica de lo inquietante familiar según la misma definición magistralmente introducida por Freud en su artículo de 1919 titulado "Das Unheimliche" y traducido en castellano como "Lo siniestro"'. Según Terry Heller en su estudio de 1987 que lleva el título de The Delights of Terror, el texto de Freud mencionado habría sellado una interpretación psicoanalítica del relato de E.T.A. Hoffmann "Der Sandmann" (1816-1817), al haberlo tomado el maestro del psicoanálisis como ejemplo para explicar la etimología de la palabra alemana "unheimlich". Freud en ese análisis habría catapultado la investigación crítico-literaria acerca de lo gótico preromántico y romántico a la jerarquía de lo prestigioso dentro del campo de estudios de textos considerados hasta entonces como triviales, por fantasiosos o fantásticos (Heller 1987 : 89). Es indudable que los estudios de Lacan alrededor de los textos literarios de Hoffmann reforzaron la idea de que las narraciones de terror merecían una atención que antes se les había negado. Sea como fuere, ninguno de los dos psicoanalistas mencionados integró su apreciación de textos literarios a una verdadera consideración acerca de la plusvalía que muchas obras producen al situar el terror gótico desde la perspectiva de los marginados del sistema (es decir, la visión femenina o infantil). Esta "minusvalía" dentro del sistema sexo-género casi nunca llamó verdaderamente la atención, dado que lo que parecía ponerse de manifiesto desde el análisis de Freud era el universalismo de los valores. Si Freud hablaba del terror como terror frente a la castración, era claro que podía centrarse en el niño varón o/y en el varón adulto, dando por sentado que lo masculino era el representante absoluto del género humano. A los varones del psicoanálisis no les interesó demasiado cuáles podían ser los miedos femeninos, puesto que la mujer no era el universal como patrón de medida de la humanidad (Amícola, 2003 : 238).

4 Lo que me interesa señalar aquí es, justamente, la intención autorial que se percibe en el relato de Silvina Ocampo en su intento de marcar debidamente la cuestión del gineceo que repite los mismos moldes de la sociedad en su conjunto ${ }^{2}$. La representación de las figuras es predominante femenina, pero esa coordenada está cruzada de modo fehaciente por la coordinada de oposiciones "adultos-infantes", donde lo que interesa es la función 
del autoritarismo ejercido dentro del propio mundo femenino. Lo más llamativo de la estrategia narrativa de Silvina Ocampo es el juego astuto entre el saber y el no saber del relator, o mejor, dicho la peculiar estrategia que le tiene preparada la autora a la función relatora. Si con razón siempre ha llamado la atención cómo se nos da en los relatos de Silvina Ocampo la historia, tal vez lo que no se ha dicho es que esta impasibilidad narrativa de muchos de los niños ocampianos frente a lo cruel es un operativo que, en definitiva, apunta a desmitificar la idea de la inocencia infantil. Las pequeñas narradoras de esta cuentista se colocan en la pose de no saber por qué ocurren las cosas, pero, al fin y al cabo, terminan aceptando, como los niños verdaderos, la maldad de las situaciones, porque se hallan más allá de toda conciencia moral.

5 La cuestión de la falta de conciencia moral de la narradora infantil se pone en evidencia también en otro cuento de 1959 (es decir, escrito dos décadas después del relato primeramente citado), titulado "El vestido de terciopelo", que comienza así :

Sudando, secándonos la frente con pañuelos, que humedecimos en la fuente de la Recoleta, llegamos a esa casa, con jardín, de la calle Ayacucho. ¡Qué risa !

Subimos en el ascensor al cuarto piso. Yo estaba malhumorada, porque no quería salir, pues mi vestido estaba sucio y pensaba dedicar la tarde a lavar y a planchar la colcha de mi camita. Tocamos el timbre : nos abrieron la puerta y entramos, Casilda y yo, en la casa con el paquete. Casilda es modista. Vivimos en Burzaco... (Silvina Ocampo/Matilde Sánchez, $1991: 167)$.

6 Una primera lectura de este relato podría hacer hincapié, gracias a las coincidencias de un estilo homogéneo, en las similitudes con el cuento anteriormente citado. Se trata otra vez, claro está, de una casa con ascensor en un barrio de la alta burguesía de Buenos Aires (Recoleta), pero a diferencia del cuento de 1937, en este caso queda explícito que la narradora es una niña que pertenece a otra condición social y que el lugar de la fábula que relata le es enteramente ajeno. El interés de cualquier mirada crítica podrá recaer en primera instancia en la oposición de clase, dada en la mención del barrio proletario de Burzaco, de donde proviene quien relata. Sin embargo, habría que prestar también atención al hecho de que nuevamente estamos ante una situación de gineceo absoluto : la modista Casilda y su pequeña acompañante pasan a entregar un vestido a la señora encumbrada que responde al ridiculizado nombre de Cornelia Catalpina y la ceremonia (que será mortal) acontece en el boudoir de ese entorno palaciego. Evidentemente la fuerza de los elementos populares enfrentados a los "habitus" de la clase alta hace que pasen inadvertidos en muchos de los cuentos de Silvina Ocampo la coordenada del género sexual. Este enfoque debe hendirse un camino para poder imponerse, dado que siempre parecería que lo que le interesaba a la autora serían las alianzas de clase y sus contradicciones. Esto ha dejado más bien oculta la particular percepción que estos relatos abren a las cuestiones sobre el género (no entendido aquí como género literario). Está claro, por supuesto, que los nombres elegidos para los personajes centrales también colaboran a esa oposición barrial y clasista antes reseñada : "Casilda" es un nombre que se ha tornado popular en la Argentina por su divulgación entre gente de campo y aledaños, mientras que "Cornelia" tiene sabor patricio y, por lo tanto, remite a lo encumbrado de la clase social que lo hace suyo. "Casilda" se opone así a "Cornelia" de modo absoluto, por cierto. Sin embargo, este no es el único enfrentamiento posible en la escritura de Silvina Ocampo, como podría serlo en otras representantes aristocráticas de su época (cf. Silvina Bullrich). Existe en esta literatura una especial mención de la situación de desvalimiento del territorio infantil, ya mencionado antes cuando aludí a "The Turn of the Screw". "Niños" versus "adultos" es, pues, una polarización que Silvina Ocampo sabe diseñar 
junto con otros maestros de la prosa del siglo XX. Lo que faltaría agregar entre esas series de contraposiciones es la de los universos antagónicos de lo masculino-femenino, aun cuando en "El vestido de terciopelo" los varones brillen por su ausencia. Aquí se trata de una relación puramente inter-femenina ; es decir, un mundo formado por mujeres, que se autoabastece. Odios, resentimientos y conjuros se desarrollan en el seno de la casa que se transforma en ominosa, a pesar de lo idílico de su entorno. Como en "Casa tomada" de Cortázar, la vivienda se va reduciendo a un sector en el cuento de Silvina Ocampo. El dormitorio pasa a ser el habitáculo por antonomasia de Cornelia. Ese es el lugar donde duerme, se viste (y tal vez ama), pero es también el lugar donde muere finalmente asfixiada por un vestido que ha querido tan estrecho como estrangulante, por una cuestión de fidelidad a sus gustos y a la elegancia, una ley de hierro dentro de sus "habitus" de clase. ¿Por qué Cornelia ha solicitado los servicios de una modista barrial para que ejecutara sus designios y no ha recurrido, en cambio, a una casa de modas de alta costura, como parece posible por su nivel económico ? Esto está callado en el relato. Tal vez Cornelia, además de elegante sea avara y su final tremebundo sea el castigo por esa infracción a un código no escrito ; casi un suicidio quizás, como auto-ajusticiamiento. Esta situación no terminaría de configurar el cuento de Ocampo, si no interviniera en él la peculiar actividad que desarrolla la función narrativa. Estamos ante la niña ocampiana por antonomasia, quien escande su relato con la frase fija y lugar común banal " $i Q u e ́$ risa!", inclusive en el más álgido de los instantes: la animalización del bordado del vestido que termina asfixiando a su dueña. Como en el "skaz", cuento popular ruso que se caracteriza por ser un relato contado ante pares y aparentemente "escuchado" como por casualidad por el lector (según lo practicó Gógol), "El vestido de terciopelo" aparece narrado para la gente menor de Burzaco. Y esta es su torsión más espectacular, porque la persona de Silvina Ocampo, escritora de la alta burguesía, elige un tour de force para meterse en el Otro, a quien interpreta por una serie de afinidades entre las que figuran la ficción nostálgica: Silvina también fue un "enfant terrible" en su infancia de gran burguesa.

7 Pasemos ahora a otro cuento de la misma autora de 1970, lo que nos llevará a abrir un arco con el de 1937 de treinta y tres años de actividad creativa. Este es el comienzo del relato de Silvina Ocampo titulado "La muñeca" en su libro Los días de la noche :

Todo el mundo dice : Yo tal cosa, yo tal otra, salvo yo que preferiría no ser yo. Soy adivina. Sospecho a veces que no adivino el porvenir, sino que lo provoco. En Las Ortigas comencé mi aprendizaje. Tengo un consultorio en La Magdalena. Nubes de polvo, la policía, mis clientes me asedian. (Silvina Ocampo/Matilde Sánchez, 1991 : 452).

La novedad que establece este nuevo texto en nuestro corpus residiría en que aquí se introduce un nuevo Leitmotiv de la obra de Silvina Ocampo : la figura de la "Adivina", pero en este caso con el dato agregado de que el personaje presenta su historia como don que se da desde la niñez. Tenemos, entonces, no solo las niñas (pertenecientes a la alta burguesía o a las clases bajas) a las que nos tiene acostumbrados la autora, sino también la propiedad sumamente característica de su pluma de brindarnos un personaje que "provoca las situaciones del futuro" en sus presagios. Esto significa que la infancia aparece ligada otra vez a cierta falta de conciencia moral, pues uno de los efectos de este don de la premonición es provocar las situaciones del futuro sin que importen sus consecuencias. 
9 Lo nuevo de este tercer texto es que la niña adivina de "La muñeca" goza de su identidad de huérfana adoptada, mezclándose no sólo con la clase alta a la que pertenece el feudo en la que la alojan, sino que ella misma empieza a identificarse con el polo varonil de sus compañeros de juegos burgueses. La niña imita en todo al otro niño rico de la estancia, Horacio, porque ama la libertad de que él dispone. La llegada de una muñeca como regalo que ella preanuncia con sus artes adivinatorias (sin saber que es para ella) termina poniéndola en su lugar -no en su lugar de huérfana adoptada-, sino en el lugar femenino. Tendrá que jugar con muñecas, en lugar de ir a bañarse con los muchachitos medio desnudos en el tanque australiano bajo el sol de la pampa. Esta corrección de género es, a mi entender, lo que la crítica literaria no ha sabido normalmente leer, entusiasmada con los otros planos de la obra cuentística de Silvina Ocampo, que da tanto pie para las oposiciones de clases sociales. La niña adoptada será obligada así, como tantas otras niñas, a adoptar la pose de género (acunando la muñeca de regalo) que la sociedad le tiene programada. Salirse de ese esquema sería lo revolucionario, por ello el cuento no termina con un castigo mayor. La niña ha recibido el premio (el regalo de la muñeca, entrevista en el sueño de sus adivinaciones), porque como mujer, ha sabido ganarse un lugar en el sistema sexo-género de la estancia (es decir, de la sociedad), cuya coronación es que acepte las leyes de la maternidad que la muñeca no hace sino predestinar, pues "on ne naît pas femme : on le devient" (Simone de Beauvoir, 1949 : I 285). La brujería que la protagonista domina desde su niñez le dará el pasaporte necesario para la aceptación de sus excentricidades ${ }^{3}$. Le será perdonado que se haya bañado mezclada con los varones, en tanto ella prometa enmendarse y volver a las muñecas, que la esperan en el recinto clausurado del hogar.

10 Haciendo un poco de historia, es oportuno decir que en 1958 había aparecido en Buenos Aires la primera traducción castellana de Le deuxième sexe (como El segundo sexo, en Editorial Leviatán) de Simone de Beauvoir y a partir de ahí esta ciudad se había caracterizado por la adoración de este texto, al menos si nos guiamos por la cantidad de traducciones que se van sumando en las décadas siguientes en la metrópolis argentina. Silvina Ocampo no podía desconocer la impronta de las ideas de la pensadora francesa, puesto que también su hermana, Victoria Ocampo, estaba en directo contacto con Simone de Beauvoir por derechos de traducción desde Sur (su revista y su editorial) y por sus afinidades con el feminismo. Es evidente que las hermanas Ocampo eran sensibles a los cambios que se anunciaban desde Francia (e Inglaterra) para la cuestión femenina y, por ello, no es inconsecuente intentar pensar los cuentos de Silvina Ocampo como una lectura especial y puesta en discurso de lo que percibe la mujer ante el mundo.

11 Ahora, bien la difusión de la obra de esta cuentista argentina se vio entorpecida por ciertas expectativas de la comunidad interpretativa a la que la autora misma pertenecía y que estaban capitaneadas por dos facciones dentro de la afamada revista Sur. Me refiero a la manera en que, por una parte, su hermana Victoria Ocampo supo ejercer su misión de operadora cultural, manteniendo bajo su égida controlada a sus "secuaces" (como el jefe de redacción de la revista José Bianco) y, por otra, el grupo indoblegable conformado por Jorge Luis Borges, Adolfo Bioy Casares y la propia Silvina Ocampo. Es necesario aquí decir que la revista Sur no solo fue el trampolín a la fama para Borges, sino que sirvió de tímida puerta de entrada para los textos de Silvina Ocampo, considerados en un primer momento por ambos bandos como no suficientemente borgeanos. En mi opinión, la aparente forma desmañada de los textos que aquí comentamos se insertaba mal en el 
proyecto decoroso y sumamente lógico de la estética que Borges estaba tratando de imponer.

12 Sea como fuere, se podría sostener que la crítica académica argentina tardó en reconocer los méritos de la obra de Silvina Ocampo, pero que a partir de la década del 80, cuando la autora estaba concluyendo su operación creativa de cincuenta años de dedicación a la literatura, los profesores universitarios rioplatenses pusieron estos cuentos insumisos en sus programas de literatura, que, en definitiva, casaban bien con los escritos por Felisberto Hernández o Julio Cortázar, autores ya consagrados en la técnica de lo inquietante familiar.

13 Es sumamente coherente con este proceso tardío de reconocimiento de la obra de Silvina Ocampo, el hecho de que a partir de un determinado momento sean los representantes más conspicuos de la revista Sur los que intenten rescatar el acervo cuentístico de esta autora. Esto sucede con la selección que lleva a cabo en 1966 José Bianco, pero también con el artículo de Sylvia Molloy en Sur de 1969 y con la reedición de La Furia y otros cuentos a cargo de Enrique Pezzoni en 1982. A este operativo de rescate se agregan esfuerzos de reconocimiento desde Estados Unidos, como el artículo de Daniel Balderston de 1983. En la Argentina, Matilde Sánchez, por su parte, aprovechará este impulso, editando en 1991 una singular antología con cuentos de esta autora. Esta última selección tiene el mérito de producir una reacción en cadena que tendrá sucesores. Sánchez no se privará de agrupar los relatos mediante una personal rotulación, reconociendo en la totalidad de esa obra una "serie de la crueldad", una "de la metamorfosis", una "de la ficción" y una "de las miniaturas", precediéndolas de lúcidas notas respectivas al rótulo que ha elegido para cada una de ellas. De esas notas, lo menos que se puede decir es que han institucionalizado un modo de leer la obra de Silvina Ocampo que, finalmente, las libera del peso de la mesura y equilibrio borgeanos. A partir de ese momento, se percibe en la recepción de esta obra el convencimiento de que se trata de un proyecto creativo personal profundamente original, gracias a lo que podríamos considerar el plus de valor que le da su perspectiva femenina. Ninguno de los escritores varones latinoamericanos nombrados más arriba pudo nunca sentir la condición de ser mujer como lo haría Silvina Ocampo (1903-1993), y para el caso también como lo había plasmado en forma de ensayo su coetánea Simone de Beauvoir (1908-1986) desde Francia.

14 En la década del 90 la mirada de algunas investigadoras viene a terminar de situar a Silvina Ocampo en el lugar que le corresponde en el panteón sudamericano, tan demoradamente alcanzado, pero, a la vez, colocándola como baluarte de una sensibilidad diferente a la de los varones que han determinado el curso de la literatura rioplatense, ahora bajo la égida cada vez más inflexible del propio Borges, del propio círculo más estricto al que perteneció la escritora que analizamos. En este punto me interesa destacar los estudios de Graciela Tomassini de 1995 y de Adriana Mancini de 2003. Ambas siguen el rumbo trazado por la antología de Matilde Sánchez, seguras de que es imposible leer la obra de Silvina Ocampo sin prestar atención a la fuerte contraposición de valores dentro del sistema sexo-género, aunque, al mismo tiempo, quede claro que sigue persistiendo la tradicional resonancia de sus cuentos en la coordenada de las clases sociales.

15 Dos generaciones separan el comienzo de la escritura de Silvina Ocampo con aquel de Marosa di Giorgio. A las niñas de Marosa ya no se las puede "poner en vereda", porque las veredas de Marosa se han hecho intangibles y vanas. En su mundo toda la corteza de la tierra es caminable como si se tratara del la superficie lisa de Deleuze. 
16 Marosa di Giorgio (1932-2004) nos dará, a diferencia de la autora anterior, una visión del mundo desordenada y caótica, donde las madres e institutrices francesas ya no tendrán ningún poder sobre las niñas. Tampoco se tratará en la obra de esta autora nacida en la pequeña ciudad uruguaya de Salto, de un mundo aristocrático y urbano, sino de la vida cotidiana entre un paisaje de chacras pueblerinas, que se tornará ominoso de puro conocido y transitado ; donde habrá espacio para que asome el lobo feroz de los cuentos de hadas, pero ahora lúbricamente aceptado para la cópula antes prohibida por madres y abuelas.

17 Llegados a este punto, es necesario hacer notar que el tratamiento de la obra de Marosa di Giorgio en estas páginas tiene como función primaria establecer un contraste con los textos cuentísticos de Silvina Ocampo. En primer lugar, conviene aclarar que la producción literaria de la escritora uruguaya posee un estatuto extraño dentro de una división esquemática de géneros literarios. Como se sabe, los textos de Marosa di Giorgio se presentan en las ediciones con subtítulos como "relatos" o "relatos eróticos", cuando, sin embargo, la postura personal de la autora es la de poeta que dedica una dicción especial a la recitación de esos textos ya de por sí ambiguos en su condición de eróticos y herejes.

18 En este sentido me parece interesante citar a una especialista sobre la lírica moderna latinoamericana. En efecto, para la investigadora norteamericana Francine Masiello, la poesía se caracterizaría, en última instancia, a través del inefable, inmaterial encanto de los ritmos, el tempo y la voz y por la capacidad de hacernos sentir la fricción de los cuerpos, pero también porque nos introduciría en un modo de estar en el mundo sin recurrir necesariamente a la razón (Francine Masiello, 2013 : 9, 52 y 58). Creo que la obra de Marosa di Giorgio nos da la posibilidad de pensar en esta condición esencial de lo poético, cuando la pensamos desde esta postura abierta de sentir la poesía.

19 Siguiendo estas ideas, habría, entonces, una esencial pose poética en los relatos en prosa de Marosa di Giorgio, cuya ilogicidad, fragmentación, ritmo y Leitmotive tienden a cruzar fronteras genéricas, en las que la idea de flujo es una constante tanto en la forma como en el contenido. De esta manera, no será extraño observar por qué nunca antes pudo hablarse de los humores de los cuerpos, especialmente femeninos, con tan gozosa manifestación. En ese sentido, la prosa poética de Marosa di Giorgio sería una escritura femenina, en tanto no habría habido nunca un varón que llegara tan lejos para asumir gozosamente los flujos corporales (de sí mismo y, menos que menos, de las mujeres). Los líquidos genitales como la menstruación pasan a ser en estos textos marosianos lugares de alborada de la feminidad que se recibe como un don. Y en esto radicaría la consustancial calidad de poéticos de estos textos que en la superficie aparecen como tramando tramas que nunca llegan a ser completas en una prosa que se entrega como cotidiana, pero que adhiere a tradiciones literarias de la infancia, como los cuentos de hadas, las canciones infantiles, los mitos bíblicos o el sinsentido lógico de Lewis Carroll.

20 Así, para uno de sus críticos, Raquel Capurro, la escritura de Marosa di Giorgio termina siendo queer, en el sentido de que aborda la sexualidad de una manera fluyente y nómada, sin establecer fronteras entre las posibilidades de acoplamiento (Raquel Capurro, 2005 : 23). Roberto Echavarren, por su parte, hará hincapié en la disolución del yo que se entroniza en la obra de la autora uruguaya, conectándola en gran medida con las ideas deleuzianas de devenir, que en estos textos aparecen como paradigmáticas (Echavarren, $2005: 16)$. 
21 Si en el caso de la obra de Silvina Ocampo, se prefirió aquí traer a cuento los comienzos de los tres cuentos del corpus elegido, dando por sentado que los inicios de un texto ponen "en una situación literaria" al lector de modo conspicuo, al establecer un pacto de lectura mediante una serie de signos que se irán encastrando a medida que avance el decurso narrativo ; para el tratamiento de la obra de Marosa di Giorgio, en cambio, se preferirá insertar dos ejemplos completos de su producción, dado que cada una de esas manifestaciones estéticas aparecen como perlas redondas imposibles de ser separadas de su conjunto. Veamos, pues, estos textos marosianos. Se hallan en su libro La flor de lis :

Había una araña que trabajaba en la pequeña selva umbrosa de la casa. En cambio de redes finas producía un crochet ancho, gris, color crema. Salía con todos los puntos perfectos, muy asegurados, ese crochet.

Mamá vino y yo la seguía con mis frágiles piernas de nueve años. Me señaló la blonda, el hilo tejido que partía la araña.

Yo miraba rígida y mamá con hábil tijera, o sólo con la mano, cortó de lo tejido y dijo : -Vamos hacia adentro.

La araña se detuvo, mas luego reemprendió la labor, sobresaltada y empecinada. De su cuerpo nacía un crochet.

Mamá aprovechó mucho de ese crochet.

Y bordó con lo robado fundas y sábanas, enaguas, corpiños. Me hizo un pañuelo para llevar a la escuela, y muchos pañuelos para la primera menstruación que ya se aproximaba. (Marosa di Giorgio, $2004: 48$ ).

En este texto tan sugerente, que es y no es una narración completa, Marosa di Giorgio aprovecha una tradición popular que liga la llegada de la menstruación con la idea de que las telas de araña calman sus efectos, para construir una situación poético-narrativa que convierte a ese evento de la pubertad de las niñas en suceso de fiesta y congratulación. Como en otros textos similares de la autora, la menstruación aparece con júbilo y debe festejarse como si fuera una boda para la que se prepara un ajuar. Lo interesante de este texto cerrado en sí mismo es también la perspectiva infantil de la mirada que eslabona el cambio púber a partir de una comparación entre la araña que genera algo de su propio cuerpo y que tiene que ver con su posición ante el mundo y su modo de vivir en él y la propia niña que también pasará dentro de poco tiempo a entregar un humor salido de su propio cuerpo, cuya manifestación la posicionará, como mujer, ante el mundo, con todo lo que esto significa para las jerarquías sociales y para la relación sexual con ese mismo mundo.

Veamos otro texto tomado del mismo libro:

La tía Glicina llegó a la tarde, en carretela negra con moños plateados. Era muy bella. Dio un breve salto y se vieron sus piernas largas, leves. Entró a la sala y se sentó junto a mi madre y sus hermanas, pero un poco más lejos con cierto aire distante. Yo me le acerqué y quería rozar su falda, azul, color de plata, y no me animaba. Ella me ofreció un paquete del que caía confitura como abejas o alhajas. No me atrevía tampoco, me fui, pero volví y pedí. Comí una yema. Ella propuso : Ve ahora, por un rato, sal.

Yo tendría seis años y salí, me escondí detrás del aparador donde había un licorero que parecía una planta. Espiaba. Y espiaba.

La señora Glicina tía, contaba : - Tuve otro...placer.

Mi madre y hermanas bajaron la cabeza ; acaso, un poco avergonzadas.

La señora Glicina dijo : - Fue con un rey.

Y entró en minucias. Repetía grititos y gemidos, suaves, picantes como ajos, ajíes oscuros. Se tocaba con dedos largos, tenuemente, las partes extremas y detallaba. Se dio vuelta y mostró la cola. Allí hizo un tintineo por largo instante. Acaso expresando : - ¡Si vieran lo que pasó aquí...en la cola ! 
Luego, púsose erguida y agregó : -Pero el amor mayor fue hecho en las tetas. Cosas de rey.

En ese momento, se oyó un fru-fru y los pezones de tía Glicina quedaron fuera. Traspasaron el tul plateado y se mostraron amoratados, violados al máximo, acaso, por un rey.

Ella aguardó unos minutos y luego dijo con voz hermosísima :

- Voy a enfriar mis tetas.

Y fue, plena de gracia, hasta la fuente, y echó agua fría en esas partes, y volvió a la silla. Los pezones se habían vuelto atrás de la gasa y miraban con ojos en espera de nuevas maravillas.

Oscureció. Y más oscureció. Todos los rostros parecían más blancos, más blancos.

Y en los lejanos altares sonó el Ángelus y empezó a formarse otra diadema.

(Marosa di Giorgio, $2004:$ 88-89).

24 El texto que antecede tiene como característica que la mirada sea desde el ángulo de percepción de una niña de seis años que se inicia en el conocimiento sexual a partir del relato de la tía. La tía Glicina le enseñará al sujeto del enunciado (la niña de seis años) a ser mujer ; es decir : eso que va a expresar el sujeto de la enunciación (Marosa di Giorgio) en su vida adulta. Dado que las tías, así como las flores, son actantes interrelacionados dentro de la obra de escritora, no será demasiado osado considerarlas juntas (tías y flores) como dispositivos semánticos de la sexualidad más exacerbada. El otro toque de "gloria" marosiana tiene que ver con la irrupción religiosa que impone al todo un sabor de espiritualidad (¿parodiada ?), como en un cuadro de Millet. Las tierras de labranza que son las del entorno de Marosa di Giorgio se regocijan tanto con la religiosidad más acendrada, como con la mayor exaltación sexual; y en esto no hay fronteras : todo fluye sin obstáculo haciendo del contenido también la forma en esa prosa que se deja decir poéticamente. Hemos dejado bien atrás el mundo selecto y exclusivo de Silvina Ocampo, donde las niñas de la clase alta miraban lo que ocurría en las escaleras de servicio desde arriba o clavaban su mirada en el cielorraso para detectar comportamientos de sus iguales. En la obra de Marosa di Giorgio hay un democratismo de las conductas y todos pertenecen a la misma clase pueblerina : tías, jardines con flores, hongos y fieras... Los cuentos del bosque se han tornado ahora eminentemente sensuales y la crueldad no existe más que como parodia, pues en este pan-sexualismo no puede haber maldad ni doble intención. Los flujos que corren como ríos de pradera en esta obra solo pueden darse en "superficies lisas", donde no se topan con ningún impedimento.

25 Según Deleuze y Guattari, desde la época griega se ha hablado de un espacio abierto como no delimitado, no fraccionado, que era el campo pre-urbano, ladera de montaña, meseta o estepa y que se oponía a la concentración urbana (Deleuze/Guattari, 1980: 489). Este espacio era concebido como una superficie lisa apta para el nomadismo, o sea para ser surcada en todas direcciones al azar. Este es el mundo que ahora instaura la obra de Marosa di Giorgio, un mundo sin veredas ni escaleras. En esto, como en muchas otras cosas, el paisaje de esa "Cornelia frente al espejo" en lo que se podrían sintetizar todos los relatos de Silvina Ocampo, aparece con espacios estriados por la costumbre y los hábitos de clase ; pero también constelados por las estrías que suponen las diferencias entre los propios y los ajenos. 


\section{BIBLIOGRAFÍA}

Amícola, José. La batalla de los géneros. La novela gótica versus la novela de educación. Rosario : Beatriz Viterbo Editora, 2003.

Balderston, Daniel. "Los cuentos crueles de Silvina Ocampo y Juan Rodolfo Wilcock". Pittsburgh : Revista Iberoamericana nำ125, oct.-dic. 1983, pp. 743-752.

Capurro, Raquel. La magia de Marosa di Giorgio. Montevideo : Lapzus, 2005.

De Beauvoir, Simone. Le deuxième sexe. París : Gallimard, 1949.

Deleuze, Gilles/Guattari, Félix. Mil mesetas. Capitalismo y esquizofrenia. Valencia : Pre-Textos, 1980.

Di Giorgio, Marosa. La flor de lis. Buenos Aires : El cuenco de plata, 2004.

Echavarren, Roberto. Marosa di Giorgio : devenir intenso. Montevideo : Lapzus, 2005.

Freud, Sigmund. "Das Unheimliche”. Gesammelte Werke, Tomo XII. Londres : Imago Publishing, 1947 (1919).

Heller, Terry. The Delights of Terror. An Aesthetics of The Tale of Terror. Urbana/Chicago : Univ. of Illinois Press, 1987.

James, Henry. The Turn of the Screw and Other Stories. Londres : Penguin Books, 1979.

Mancini, Adriana. Silvina Ocampo. Escalas de pasión. Buenos Aires : Norma, 2003.

Masiello, Francine. El cuerpo y la voz (poesía, ética y cultura). Rosario : Beatriz Viterbo Editora, 2013.

Molloy, Sylvia. "Silvina Ocampo : la exageración como lenguaje”. Buenos Aires : Sur, No. 32, set.oct. 1969, pp. 14-24.

Ocampo, Silvina. El pecado mortal. Buenos Aires : EUDEBA, 1966.

Ocampo, Silvina. La furia y otros cuentos. Madrid : Alianza, 1982.

Ocampo, Silvina. Las reglas del secreto. Antología. (Selección, prólogo y notas de Matilde Sánchez), México /Buenos Aires : Fondo de Cultura Económica, 1991.

Pezzoni, Enrique. "Silvina Ocampo. La nostalgia del orden" en Silvina Ocampo. La furia y otros cuentos. Madrid : Alianza, 1982, pp. 9-23.

Tomassini, Graciela. El espejo de Cornelia : la obra cuentística de Silvina Ocampo. Buenos Aires : Plus Ultra, 1995.

\section{NOTAS}

1. La traducción al francés de este término suele darse como "l'inquiétante étrangeté" y en inglés como "the Uncanny".

2. La cuestión de la "intención del autor" ha sido muy discutida en la crítica literaria. Creo, por mi parte, que no hay que tenerle miedo al sintagma, si se diferencia del "mensaje de autor" y del resultado que es la obra final en su relación con sus lectores. Estoy convencido de que siempre 
hay una intención autorial que puede (o no) canalizarse finalmente con éxito en la obra. La intención autorial puede advertirse en los para-textos literarios y también en la obra misma.

3. "Sorcière" llama la institutriz francesa a la pequeña protagonista.

\section{RESÚMENES}

La intención de las siguientes reflexiones es redirigir la discusión crítica acerca de la obra de la escritora argentina Silvina Ocampo, de modo tal que el material para la polémica que abren sus cuentos permita no sólo enfocar las coordenadas de clase (presentes siempre gracias a su pertenencia a la alta burguesía), sino también otro aspecto que hasta ahora no ha merecido suficiente atención como lo serían las cuestiones de género sexual. Para llegar a este cometido se han elegido aquí tres cuentos de la autora en los que la voz narrativa está articulada por una niña. Los ejemplos serán tomados de los inicios de los cuentos "Cielo de claraboyas" (de 1937), "El vestido de terciopelo" (de 1959) y "La muñeca” (de 1970). De esta manera, el corpus elegido para reflexionar sobre la obra de Silvina Ocampo abarcará más de tres décadas de actividad literaria, hecho que hará evidente la continuidad de su proyecto. A modo de contraposición, se hablará también de la producción literaria de la autora uruguaya Marosa di Giorgio, nacida tres décadas después de la escritora argentina y originaria de la pequeña-burguesía, cuya relación con la sexualidad aparece irónicamente menos limitada por los habitus de clase.

L'intention des réflexions qui suivent est de déplacer la réflexion sur l'œuvre littéraire de Silvina Ocampo vers un nouveau centre, en nous focalisant non seulement sur la confrontation entre les classes sociales dans ses nouvelles, mais aussi sur le rôle qu'y joue le genre. Les exemples analysés seront tirés des incipits de "Cielo de claraboyas » (1937), «El vestido de terciopelo » (1959) et «La muñeca » (1970), où la voix narrative est celle d'une enfant. Le corpus couvrira plus de trois décennies d'activité littéraire. En contrepoint de cette sélection de textes, il sera également question de l'œuvre de l'Uruguayenne Marosa di Giorgio. Issue, contrairement à Silvina Ocampo, de la petite et non de la haute bourgeoisie, Marosa di Giorgio semble ironiquement plus affranchie de ses habitus de classe et, par là, plus libre dans l'expression de sa sexualité.

The intention of the next pages is to draw attention to a new field of discussion on the Argentinean writer Silvina Ocampo's literary works, focusing the analysis not only on the subject of class confrontation in her narrative but also on gender questions. We will consider the beginnings of three short stories, spanning three decades of her production -"Cielo de claraboyas" (1937), "El vestido de terciopelo" (1959) and "La muñeca" (1970)- where the narrative voice is that of a little girl. In opposition to this literary project, we will also study the Uruguayan writer Marosa di Giorgio's literary work, who did not come from the high bourgeoisie like Silvina Ocampo but from a lower social class. Ironically, she had less to lose by risking positions on the subject of sexuality and could therefore show more freedom in the expression of desires. 


\section{ÍNDICE}

Mots-clés: gothique, divination, flux, lisse, strié

Palabras claves: gótico, adivinación, flujo, liso, estriado

Keywords: gothic, divination, flow, smooth, triated

\section{AUTOR}

JOSÉ AMÍCOLA

Universidad Nacional de La Plata 